\title{
The mean-variance relation and the role of institutional investor sentiment
}

Wenzhao Wang*

Newcastle University Business School

\begin{abstract}
This paper investigates the role of institutional investor sentiment in the mean-variance relation.

We find market returns are negatively (positively) related to market's conditional volatility over bullish (bearish) periods. The evidence indicates institutional investors to be sentiment traders as well.
\end{abstract}

JEL classification: G12; G14; G41

Keywords: Institutional investor sentiment; Mean-variance relation; Risk-return tradeoff

\footnotetext{
*Wenzhao Wang, Newcastle University Business School, 5 Barrack Road, Newcastle, UK, NE1 4SE. Telephone: +44(0) 1912081500.

E-mail:w.wang22@newcastle.ac.uk.
} 


\section{The mean-variance relation and the role of institutional investor sentiment}

\section{Introduction}

Rational asset pricing theories posit a positive mean-variance relation, i.e. the risk-return tradeoff. However, empirical evidence is quite mixed. ${ }^{1}$ From a behavioral approach, Yu and Yuan (2011) state that unsophisticated investors are likely to misestimate variance of returns and they prefer taking long positions to short positions. Hence, an elevated level of unsophisticated investors over high-sentiment periods would distort the positive mean-variance relation while over low-sentiment periods, the positive relation would appear, which is empirically supported by their findings.

Extending Yu and Yuan (2011), we offer a new perspective by probing the role of institutional investor sentiment in determination of the mean-variance relation. While institutional investors are typically regarded sophisticated and are less likely to succumb to mises timation of variance of returns, more recent research by DeVault et al. (2018) show that in contrast to theoretical models, institutional rather than individual investors tend to be sentiment traders. Based on these, we argue that if institutional investors are sentiment traders, the distorted risk-return tradeoff would be observed when institutional investor sentiment is high.

\section{Sentiment, market returns, and volatility models}

\subsection{Institutional investor sentiment}

We collect institutional investor sentiment data from Investors Intelligence (II) that compiles weekly sentiment from investment newsletter writers including current or retired professionals who categorize themselves as bullish, bearish, or neutral (Brown and Cliff, 2004). The II considers the norm sentiment level to be $45 \%$ bulls, $35 \%$ bears, and $20 \%$ neutral, indicating

\footnotetext{
${ }^{1}$ Extant evidence on the mean-variance relation appears three streams: positive, negative, and mixed (see, e.g., French et al., 1987; Whitelaw, 1994; Rossi and Timmermann, 2015; Wang et al., 2017).
} 
that when the proportion of bulls (Bull\%) exceeds $45 \%$, institutional investors would generally be bullish and when the proportion of bears (Bear\%) is over $35 \%$, they would normally be bearish. Unlike Yu and Yuan (2011) grouping the entire sample into high- and low-sentiment subsamples, we split ours into bullish, bearish, along with neutral subsamples. This is because separately exploring neural periods provides the standard state of the mean-variance relation when institutional investors are neither optimistic nor pessimistic, which seems more realistic in practice.

The approach to identify sentiment regimes largely follows Yu and Yuan (2011) and Antoniou et al. (2016). One period is at least one year to avoid too frequent conversions between three regimes. We compute annual Bull\% and Bear\% in calendar year $T$ by averaging the weekly Bull\% and Bear\% within the calendar year $T$, which is used to classify the sentiment regime for the next calendar year $(T+1)$. In particular, the next calendar year $(T+1)$ is categorized into bullish if Bull\% is over $45 \%$, bearish if Bear\% is over 35\%, and neutral otherwise.

While our separation is based on the II, one concern is that we do not disentangle the impact of individual investor sentiment - that is, this separation may reflect individual investor sentiment given its potential synchronous trend with institutional investor sentiment. If it is the case, our separation would not exclusively reflect the role of institutional investor sentiment in the mean-variance relation. To address this issue, we compute the correlation between Bull\% and four widely-applied individual investor measures including consumer confidence of the Conference Board, consumer sentiment of the University of Michigan, and raw and orthogonalized BW sentiment index from Baker and Wurgler (2006). ${ }^{2}$ The unreported correlations are $0.141($ prob. $=0.001), 0.332($ prob. $=0.000),-0.122($ prob. $=0.039)$, and -

\footnotetext{
${ }^{2}$ We consider Bull\% here since high (low) sentiment corresponds to high (low) values in Bull\%, which is consistent with other individual investor sentiment measures. However, for Bear\%, high (low) sentiment corresponds to low (high) values in Bear\%, which is not commonly used in individual investor sentiment proxies.
} 
$0.106($ prob. $=0.013)$, respectively, all of which are not prohibitively high. In this sense, our separation is mainly driven by institutional investor sentiment.

Table 1 shows that the historical averages of Bull\% and Bear\% are 0.453 (45.3\%) and 0.310 $(31.0 \%)$, respectively. In our sample containing 46 years, 24 and 14 years are identified as bullish and bearish periods, accordingly. The rest 8 years are then neutral periods. The movement of historical Bull\% and Bear\% is illustrated in Figure 1, exhibiting that institutional investor sentiment fluctuates around the norm level, but at times it can deviate from the norm a lot.

Table 1: Summary statistics of Bull\% and Bear\%, 1970-2015.

\begin{tabular}{lccccc}
\hline & $\boldsymbol{\mu}$ & $\boldsymbol{\sigma}$ & Max. & Min. & Number of years \\
\hline Bull\% & 0.453 & 0.099 & 0.844 & 0.163 & 24 \\
Bear\% & 0.310 & 0.092 & 0.487 & 0.118 & 14 \\
\hline
\end{tabular}

This table presents the summary statistics of Bull\% and Bear\%. In particular, we report the mean $(\sigma)$, the standard deviation $(\sigma)$, the maximum value (Max.), the minimum value (Min.), and the number of years for each subsample.

Figure 1: Historical Bull\% and Bear\% weekly movement, 1970-2015.

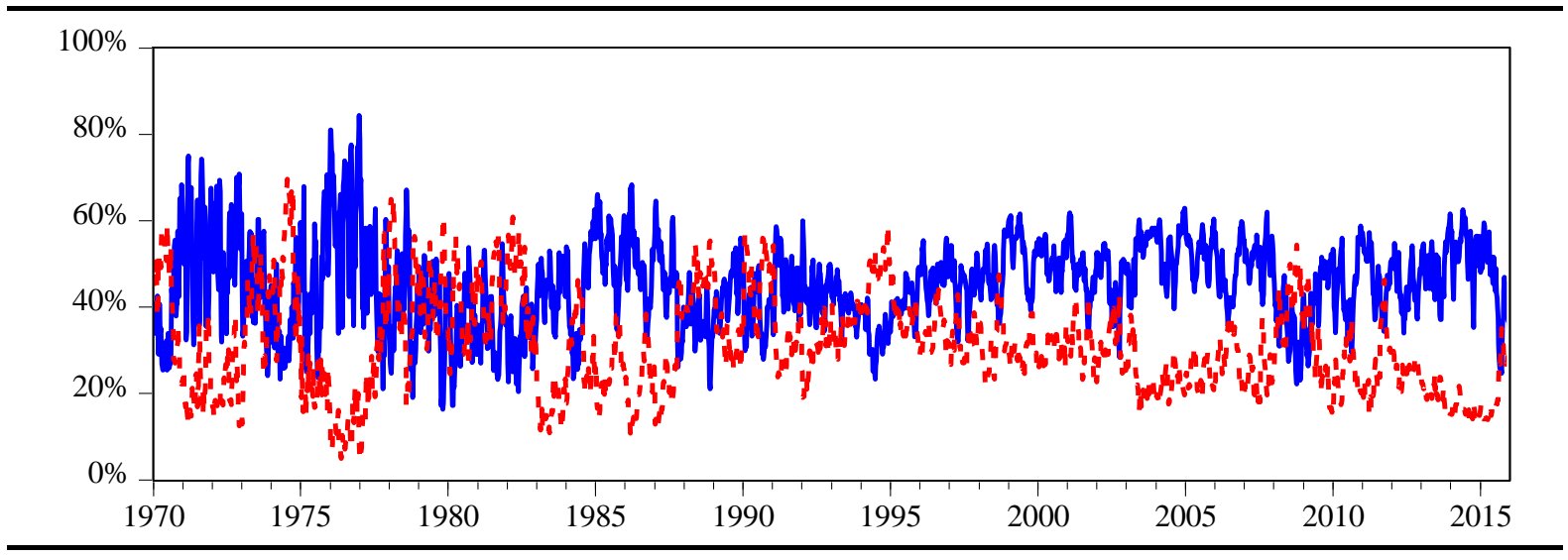

This figure presents the historical Bull\% and Bear\% weekly movement from 1970 to 2015. The solid and dotted lines represent Bull\% and Bear\%, respectively.

\section{$2.2 \quad$ Stock market}

We collect value- and equal-weighted NYSE/AMEX market returns from the CRSP compiled by the WRDS. Table 2 shows that the mean of realized volatility is, by definition, close to the 
variance of market returns, and the difference between two figures is due to Jensen's inequality (Ghysels et al., 2005).

Table 2: Summary statistics of NYSE/AMEX market returns, 1971-2016.

\begin{tabular}{|c|c|c|c|c|c|c|c|c|}
\hline & \multicolumn{4}{|c|}{ Excess market returns } & \multicolumn{4}{|c|}{ Realized volatility } \\
\hline & $\mu$ & $\sigma^{2}$ & Skew. & Kurt. & $\mu$ & $\sigma^{2}$ & Skew. & Kurt. \\
\hline Value-weighted & 0.533 & 0.188 & -0.515 & 2.451 & 0.213 & 0.189 & 8.695 & 92.533 \\
\hline Equal-weighted & 0.738 & 0.283 & -0.066 & 4.973 & 0.161 & 0.156 & 8.464 & 84.977 \\
\hline
\end{tabular}

This table presents the summary statistics of NYSE/AMEX market returns. In particular, we report the mean $(\mu)$, the variance $\left(\sigma^{2}\right)$, the skewness (Skew.), and the kurtosis (Kurt.) for excess market returns and realized volatility. Realized volatility is computed from within-month daily market returns. The mean and the variance for excess market returns are multiplied by 100 . The mean and the variance for realized volatility are multiplied by 100 and 10,000, respectively.

\subsection{Volatility models}

To measure conditional variance, we adopt four approaches including the rolling window (RW),

GARCH, GJR-GARCH, and EGARCH models considering that the presented mean-variance relation depends on the choice of volatility models (Ghysels et al., 2005). The RW model follows,

$$
\operatorname{Var}_{t}\left(R_{t+1}\right)=\sigma_{t}^{2}=\frac{22}{N_{t}} \sum_{d=1}^{N_{t}} r_{t-d}^{2}
$$

where $\operatorname{Var}_{t}\left(R_{t+1}\right)$ is conditional volatility for forecasting next-month market returns $R_{t+1} ; \sigma_{t}^{2}$ is realized volatility in month $t ; r_{t-d}$ is the demeaned daily return in month $t$, computed by subtracting the within-month mean daily return from the daily raw returns; $N_{t}$ is the actual number of trading days in month $t$, and 22 is the conventionally adopted number of trading days in one month. For GARCH, GJR-GARCH, and EGARCH models, we first estimate the mean equation,

$$
r_{t+1}=\mu+\varepsilon_{t+1},
$$


where $r_{t+1}$ is the daily market return at day $(t+1) ; \mu$ is the conditional mean of the daily return. The daily conditional volatility of market returns is filtered from,

$$
\begin{aligned}
& \sigma_{t+1}^{2}=\omega+\alpha \varepsilon_{t}^{2}+\beta \sigma_{t}^{2}, \\
& \sigma_{t+1}^{2}=\omega+\alpha_{1} \varepsilon_{t}^{2}+\alpha_{2} I_{t} \varepsilon_{t}^{2}+\beta \sigma_{t}^{2}, \\
& \sigma_{t+1}^{2}=\exp \left\{\omega+\alpha_{1}\left[\left|\varepsilon_{t}\right| / \sqrt{\sigma_{t}^{2}}\right]+\alpha_{2}\left[\varepsilon_{t} / \sqrt{\sigma_{t}^{2}}\right]+\beta \ln \sigma_{t}^{2}\right\},
\end{aligned}
$$

for GARCH, GJR-GARCH, and EGARCH models, accordingly. The term $I_{t}$ in Eq. (4) is the dummy variable for good news to account for the leverage effect (Glosten et al., 1993). We store daily conditional volatility series from these three specifications and apply them to the following,

$$
\operatorname{Var}_{t}\left(R_{t+1}\right)=E_{t}\left(\sum_{d=1}^{N_{t}} \sigma_{t+d}^{2}\right)
$$

where the monthly conditional volatility, $\operatorname{Var}_{t}\left(R_{t+1}\right)$, is computed from the linear sum of daily conditional volatility, as specified in Engle (2001).

\section{Empirical results}

To test the mean-variance relation, we estimate,

$$
R_{t+1}=\alpha+\beta \operatorname{Var}_{t}\left(R_{t+1}\right)+\xi_{t+1}
$$

To discriminate the mean-variance relation over bullish, bearish, and neutral periods, we adopt,

$$
\begin{aligned}
R_{t+1}= & \alpha_{1}+\alpha_{2} D_{1, t}+\alpha_{3} D_{2, t}+\beta_{1} \operatorname{Var}_{t}\left(R_{t+1}\right)+\beta_{2} D_{1, t} \operatorname{Var}_{t}\left(R_{t+1}\right)+\beta_{3} D_{2, t} \operatorname{Var}_{t}\left(R_{t+1}\right)+ \\
& \xi_{t+1},
\end{aligned}
$$


where $D_{1, t}$ is one for bullish periods and zero otherwise; $D_{2, t}$ is one for bearish periods and zero otherwise. Therefore, $\beta_{1},\left(\beta_{1}+\beta_{2}\right)$, and $\left(\beta_{1}+\beta_{3}\right)$ are the mean-variance relations over neutral, bullish, and bearish periods, accordingly.

We hypothesize that as institutional investors are sentiment traders (DeVault et al., 2018), their increased participation over bullish periods would distort the positive mean-variance relation, while the risk-return tradeoff would appear over bearish periods.

Table 3: Excess market returns against conditional variances

\begin{tabular}{|c|c|c|c|c|c|c|c|c|}
\hline \multirow[b]{2}{*}{ Method } & \multicolumn{2}{|c|}{ Entire sample (I) } & \multicolumn{6}{|c|}{ Neutral, bullish, and bearish periods (II) } \\
\hline & $\boldsymbol{\beta}$ & prob. & $\beta_{1}$ & prob. & $\beta_{1}+\beta_{2}$ & prob. & $\beta_{1}+\beta_{3}$ & prob. \\
\hline \multicolumn{9}{|c|}{ Panel A Value-weighted returns } \\
\hline RW & -1.015 & $(0.017)^{\mathrm{b}}$ & -0.798 & $(0.631)$ & -1.403 & $(0.002)^{\mathrm{a}}$ & 2.838 & $(0.043)^{\mathrm{b}}$ \\
\hline GARCH & -0.629 & $(0.2$ & 1.386 & $(0.5$ & -1.359 & $(0.027)^{b}$ & 3.903 & $(0.020)^{\mathrm{b}}$ \\
\hline GJR-GARCH & -0.697 & $(0$. & 0.756 & $(0.7$ & -1.204 & $(0.033$ & 3.755 & $(0.035)^{\mathrm{b}}$ \\
\hline EGARCH & -0.776 & $(0.299)$ & 1.996 & $(0.414)$ & -1.890 & $(0.025)^{b}$ & 4.467 & $(0.031)^{\mathrm{b}}$ \\
\hline \multicolumn{9}{|c|}{ Panel B Equal-weighted returns } \\
\hline RW & -0.412 & $(0.472)$ & -1.405 & $(0.404)$ & -1.728 & $(0.028)^{b}$ & 5.471 & $(0.000)^{2}$ \\
\hline GARCH & -0.009 & $(0.990)$ & -0.801 & $(0.748)$ & -1.407 & $(0.079)^{\mathrm{c}}$ & 6.756 & $(0.000)^{2}$ \\
\hline GJR-GARCH & -0.242 & $(0.725)$ & -1.190 & $(0.614)$ & -1.376 & $(0.072)^{\mathrm{c}}$ & 7.393 & $(0.000)^{2}$ \\
\hline EGARCH & 0.021 & $(0.983)$ & -0.017 & $(0.996)$ & -1.904 & $(0.088)^{\mathrm{c}}$ & 9.238 & $(0.000)^{2}$ \\
\hline
\end{tabular}

This table presents results of the mean-variance relation over the entire sample (Column I) along with over neutral, bullish, and bearish periods (Column II).

${ }^{a},{ }^{b}$, and ${ }^{c}$ represent statistical significance at the $1 \%, 5 \%$, and $10 \%$ level, respectively.

Table 3 presents that the mean-variance relation in the entire sample is negative for both valueand equal-weighted returns except for one trivial case. Notably, the RW model presents the significantly negative mean-variance relation for the value-weighted returns. Therefore, our results support one stream of extant empirical evidence on mixed findings, but do not support the other streams.

Clearly, the mean-variance relation varies across neutral, bullish, and bearish periods. It is quite mixed over neutral periods, from $-0.798(\mathrm{RW})$ to $1.996(\mathrm{EGARCH})$ and from $-1.405(\mathrm{RW})$ to -0.017 (EGARCH) for value- and equal-weighted returns, respectively. In a consistent manner, 
no relation is significant. However, we find a significant risk-return tradeoff over bearish periods across all volatility models. For example, according to the GARCH model, a $1 \%$ increase (decrease) in conditional volatility would lead to a $3.903 \%$ increase (decrease) in value-weighted market returns. By contrast, the positive relation crashes and becomes negative over bullish periods. For a same magnitude of movement in conditional volatility, i.e., $1 \%$ increase (decrease), a 1.359\% decrease (increase) in value-weighted returns would be expected based on the GARCH model.

In line with our hypothesis, the findings indicate that when institutional investors are bearish, their reluctance to trade would not distort the risk-return tradeoff; on the contrary, when they feel bullish, their elevated trading would breach the risk-return tradeoff. Implications of our findings are twofold: First, like individual investors, institutional investors would affect the mean-variance relation as well, and second, institutional investors are also sentiment traders, consistent with DeVault et al. (2018).

\section{Acknowledgements}

We thank Constantinos Antoniou at Warwick Business School (UK) and Jinyu Feng at Shandong University of Finance and Economics (China) for useful comments. 


\section{References}

Antoniou, C., Doukas, J.A., Subrahmanyam, A., 2016. Investor sentiment, beta, and the cost of equity capital. Manag. Sci. 62 (2), 347-367. http://dx.doi.org/10.1287/mnsc.2014.2101.

Baker, M., Wurgler, J., 2006. Investor sentiment and the cross-section of stock returns. J. Finance 61 (4), 1645-1680. http://dx.doi.org/10.1111/j.1540-6261.2006.00885.x.

Brown, G.W., Cliff, M.T., 2004. Investor sentiment and the near-term stock market. J. Empir. Finance 11 (1), 1-27. https://doi.org/10.1016/j.jempfin.2002.12.001.

DeVault, L., Sias, R., Starks, L., 2018. Sentiment metrics and investor demand. J. Finance, forthcoming.

Engle, R.F., 2001. GARCH 101: the use of ARCH/GARCH models in applied econometrics. J. Econ. Perspect. 15 (4), 157-168. http://dx.doi.org/10.1257/jep.15.4.157.

French, K.R., Schwert, W., Stambaugh, R.F., 1987. Expected stock returns and volatility. J. Financ. Econ. 19 (1), 3-29. http://dx.doi.org/10.1016/0304-405X(87)90026-2.

Ghysels, E., Santa-Clara, P., Valkanov, R., 2005. There is a risk-return trade-off after all. J. Financ. Econ. 76 (3), 509-548. http://dx.doi.org/10.1016/j.jfineco.2004.03.008.

Glosten, L.R., Jagannathan, R., Runkle, D.E., 1993. On the relation between the expected value and the volatility of the nominal excess return on stocks. J. Finance 48 (5), 1779-1801. http://dx.doi.org/10.1111/j.1540-6261.1993.tb05128.x.

Rossi, A.G., Timmermann, A., 2015. Modeling covariance risk in Merton's ICAPM. Rev. Financ. Stud. 28 (5), 1428-1461. http://dx.doi.org/10.1093/rfs/hhv015.

Wang, H., Yan, J., Yu., J., 2017. Reference-dependent preferences and the risk-return tradeoff. J. Financ. Econ. 123 (2), 395-414. https://doi.org/10.1016/j.jfineco.2016.09.010.

Whitelaw, R.F., 1994. Time variations and covariations in the expectation and volatility of stock market returns. J. Finance 49 (2), 515-541. http://dx.doi.org/10.1111/j.15406261.1994.tb05150.x.

Yu, J., Yuan, Y., 2011. Investor sentiment and the mean-variance relation. J. Financ. Econ. 100 (2), 367-381. http://dx.doi.org/10.1016/j.jfineco.2010.10.011. 